\title{
FUNDAMENTOS DE GEOMETRIA FRACTAL E SUAS APLICAÇÕES NA EDUCAÇÃO BÁSICA
}

\author{
AUTOR: LUCIANO BELEM SANTOS \\ CO-AUTOR: EVERLON SOUZA CAMPOS \\ CO-AUTOR/ORIENTADOR: ADRIANO DE JESUS DA SILVA
}

Resumo: A geometria oferece formas inovadoras e úteis tanto para investigações em pesquisa como em ensino de ciência básica e tecnologia. Contudo, o ensino deste importante ramo da matemática ainda representa um grande desafio para o docente. Como consequência observa-se altos índices de rejeição acompanhados de níveis insuficientes de aprendizado. Dentro deste contexto, pode-se destacar uma apresentação inadequada do formalismo matemático, bem como a ausência de aplicações que facilitem a assimilação do tópico em estudo. Observando a natureza, percebe-se que muitas figuras e objetos adquirem formas que se repetem. Essas repetições chegam a tal ponto que não consegue-se mais serem vistas a olho nu. Matemáticos, principalmente Benoît Mandelbrot, resolveram analisar melhor tais acontecimentos e perceberam que existiam meios de provar tais estruturas através de cálculos matemáticos. Essas figuras são os fractais, que são objetos em que a sua figura principalmente se repete indefinidamente. Ao analisar os fractais vê-se que é uma forma diferente de ensinar a matemática, principalmente a geometria que existe nos objetos e figuras que são formadas neles e por eles. O presente projeto foi importante para o aprendizado acerca dos fundamentos da geometria fractal e da construção de sequências didáticas, nela baseadas, para serem aplicadas no ensino básico, principalmente com a utilização de programa de computador que auxilia nessas sequências e é um jeito diferente dos estudantes aprenderem.

Palavras-chave: Matemática, geometria fractal, educação básica, geogebra. 